Supporting Information

\title{
Spreading Dynamics of a Precursor Film of Ionic Liquid or Water on a Micropatterned Polyelectrolyte Brush Surface
}

Shohei Shiomoto, ${ }^{1}$ Hayato Higuchi, ${ }^{1}$ Kazuo Yamaguchi, ${ }^{2}$ Hiromitsu Takaba, ${ }^{2}$ and Motoyasu Kobayashi $i^{*}$

${ }^{1}$ Graduate School of Engineering, Kogakuin University, Tokyo 192-0015, Japan

${ }^{2}$ School of Advanced Engineering, Kogakuin University, Tokyo 192-0015, Japan

*Address correspondence to Motoyasu Kobayashi

School of Advanced Engineering, Kogakuin University, 2665-1 Nakanomachi, Hachioji,

Tokyo 192-0015, Japan

Phone: +81-42-628-4551, Fax: +81-42-628-4551

E-mail: motokoba@cc.kogakuin.ac.jp

\section{S1. Preparation of Poly(SPMK) Brush/FAS Monolayer Line-Patterned Surface}

The glass slides used as a substrate (Matsunami Glass Ind., borosilicate glass, thickness = $0.8-1.0 \mathrm{~mm}$, root mean square roughness was $0.98 \mathrm{~nm}$ on area of $30 \times 30 \mu \mathrm{m}^{2}$ by AFM topological measurement) were cut into $26 \times 38 \mathrm{~mm}^{2}$ pieces. The substrates were immersed in a $\mathrm{H}_{2} \mathrm{SO}_{4} / 35 \% \mathrm{H}_{2} \mathrm{O}_{2}$ aq. $(70 / 30 \mathrm{v} / \mathrm{v})$ mixture at $373 \mathrm{~K}$ for $1 \mathrm{~h}$ to obtain a $\mathrm{Si}-\mathrm{OH}$-terminated surface. The substrates were subjected to vacuum ultraviolet (VUV) treatment ( $\lambda=172 \mathrm{~nm}$, Xe excimer lamp, UER20-172, Ushio Electric, Ltd.) at a pressure of 60-70 Pa for $6 \mathrm{~min}$. The 
surface initiator, BHM, was immobilized on the glass substrates by CVA as follows. The substrates and a glass vessel filled with a $5 \mathrm{vol} \%$ toluene solution of BHM were packed in a custom-made separable flask (inside diameter: $75 \mathrm{~mm}$, height: $105 \mathrm{~mm}$ ) purged with $\mathrm{N}_{2}$ gas. The flask was held in an oven at $418 \mathrm{~K}$ for $7 \mathrm{~h}$, after which the substrates were rinsed with ethanol.

The BHM-immobilized substrates were placed in an evacuated vacuum chamber for photolithography. Each substrate was covered with a photomask (L10S5, Mitani Micronics Co., Ltd.) with $10 \mu \mathrm{m} \mathrm{Cr}$ lines and $5 \mu \mathrm{m}$ slits $(10 \mu \mathrm{m} / 5 \mu \mathrm{m})$ in an area of $30 \times 30 \mathrm{~mm}^{2}$ on a quartz glass plate with a thickness of $2.3 \mathrm{~mm}$. Two stainless steel rings (outside diameter: 60 $\mathrm{mm}$, inside diameter: $30 \mathrm{~mm}$, height: $9.5 \mathrm{~mm}$, weight: $160 \mathrm{~g}$ per piece) were loaded on the photomask. The surface was irradiated for $360 \mathrm{~s}$ by VUV light at 20-40 $\mathrm{Pa}$. To remove the decomposed residue of the BHM monolayers, the patterned surface was rinsed with ethanol. A second organosilane monolayer of FAS was then introduced between the lines of the first patterned monolayer of BHM using a similar CVA method. The substrates and a glass vessel filled with FAS were packed in the separable flask purged with $\mathrm{N}_{2}$ gas and then heated at 373 $\mathrm{K}$ for $3 \mathrm{~h}$, after which the substrates were rinsed with ethanol. By this method, line-patterned BHM monolayer and FAS monolayer surfaces with line widths of 10 and $5 \mu \mathrm{m}$, respectively, were prepared.

Poly(SPMK) brushes were prepared using surface-initiated activators generated by electron transfer (AGET) ATRP of SPMK from the residual BHM monolayer on the line-patterned surface. The SPMK $(8.12 \mathrm{mmol}), \mathrm{CuBr}_{2}(8.1 \mu \mathrm{mol})$, bpy $(16.6 \mu \mathrm{mol})$, deionized water $(6.0 \mathrm{~mL})$, and methanol $(14.0 \mathrm{~mL})$ were mixed and applied to the substrate in a glass tube. After the mixture was stirred under a stream of $\mathrm{N}_{2}$ gas for $30 \mathrm{~min}$, a $0.20 \mathrm{M}$ ascorbic acid aqueous solution $(8.2 \mu \mathrm{mol})$ was added as a reducing agent to initiate polymerization. The mixture was stirred under $\mathrm{N}_{2}$ atmosphere at $303 \mathrm{~K}$ for $3 \mathrm{~h}$. Polymerization was terminated by opening the vessel to air. The substrate was rinsed successively with deionized water, ethylene glycol, and deionized water; it was then dried by air blowing. 


\section{S2. AFM observation of the Line-Patterned Surface}

AFM (NanoWizard 3 Ultra, JPK Instruments AG) was used in the dynamic force mode at room temperature. Imaging was performed under ambient atmosphere to measure the brush thickness in the dry state. Rectangular silicon cantilevers with a backside gold coating (HyperDrive PPP-NCHAuD, Nanosensors, NanoWorld AG, tip radius: $7 \mathrm{~nm}$, spring constant: $42 \mathrm{~N} \mathrm{~m}-1$, resonance frequency: $330 \mathrm{kHz}$ ) were used for imaging. Imaging was performed by scanning an area of $30 \times 30 \mu \mathrm{m} 2$ transverse to the line pattern.

(a)

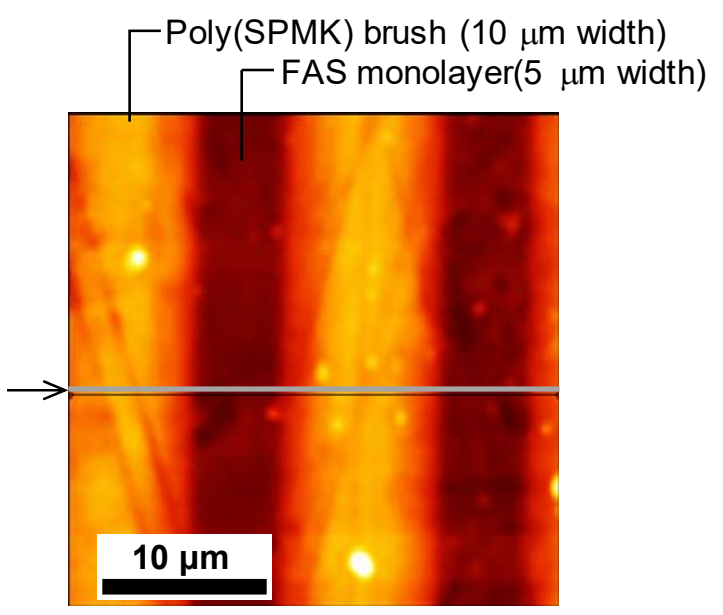

(b)

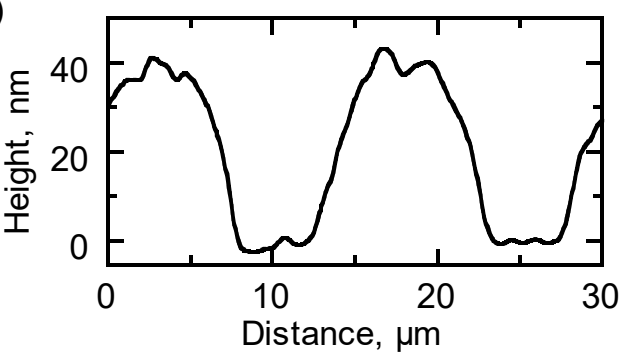

Figure S1. (a) The AFM topography images and (b) the cross sections of the poly(SPMK) brush and FAS monolayer line-patterned surfaces with line widths of $10 \mu \mathrm{m}$ and $5 \mu \mathrm{m}$ in the dry state. The brush thicknesses were measured as $39 \mathrm{~nm}$ on the surface. The imaging was performed under ambient atmosphere at room temperature.

\section{S3. XPS Analysis of Line-Patterned Surface}

XPS (Quantum 2000 Scanning ESCA Microprobe, Physical Electronics, Inc.) was operated with a monochromatized $\mathrm{Al} \mathrm{K \alpha} \mathrm{X}$-ray source at $1.48 \mathrm{keV}$ at $24.7 \mathrm{~W}$ under $1 \times 10^{-6}$ 
Pa. The emission angle of photoelectrons was set to $45^{\circ}$ and the beam diameter was $100.0 \mu \mathrm{m}$. The neutralizer was set at $1.0 \mathrm{~V}$ and $20.0 \mu \mathrm{A}$. Wide-scan spectra $(0-800 \mathrm{eV})$ were acquired at an energy step of 1.0 and high-resolution spectra (narrow scan) of $F_{1 s}, K_{2 p}, C_{1 s}$ and $S_{2 p}$ were at $0.125 \mathrm{eV}$. As shown in Figure S2, $\mathrm{F}_{1 \mathrm{~s}}, \mathrm{~K}_{2 \mathrm{p}}$, and $\mathrm{S}_{2 \mathrm{p}}$ peaks corresponding to the poly(SPMK) brush and FAS monolayer.

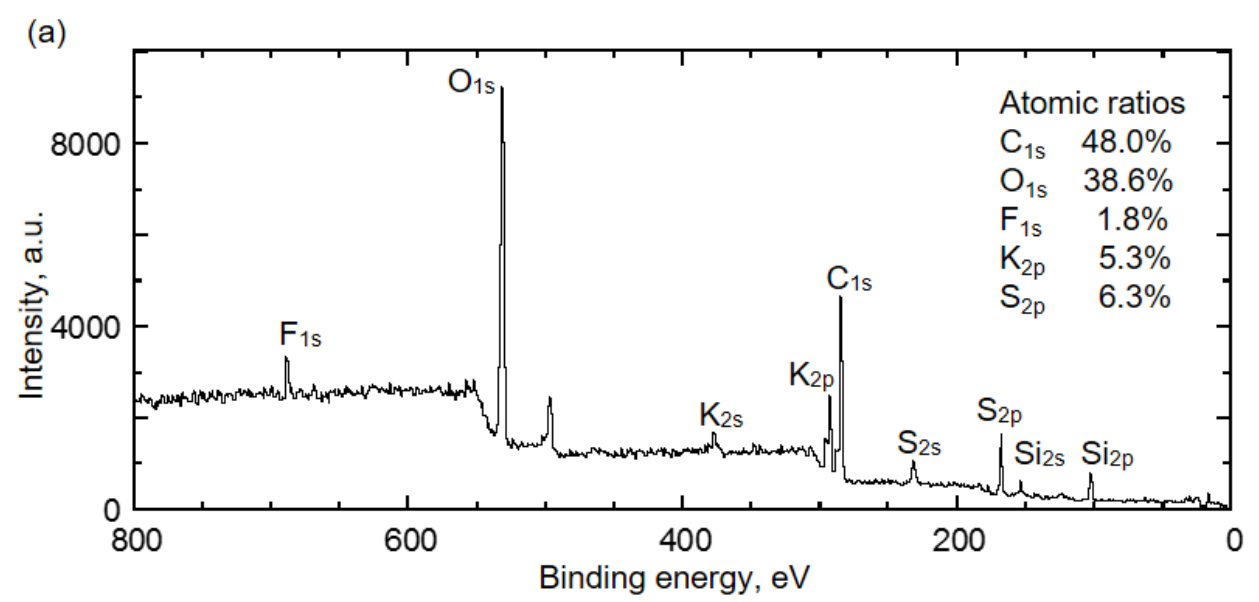

(b)

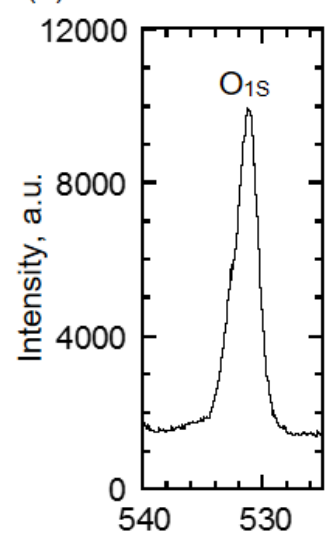

(c)

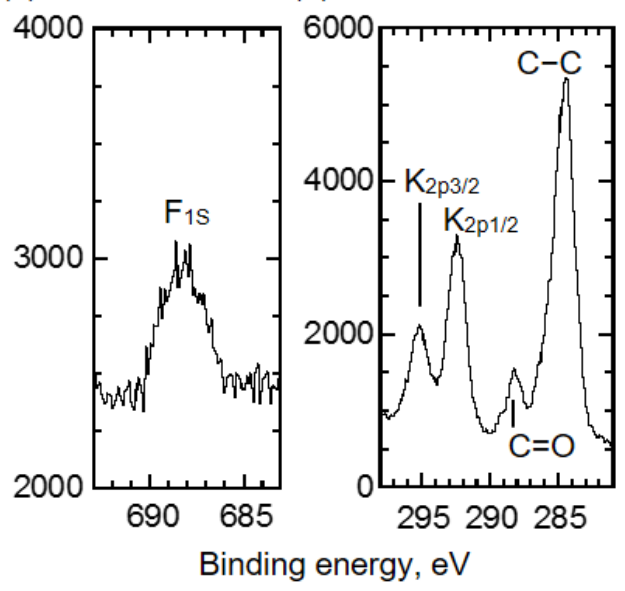

(e)

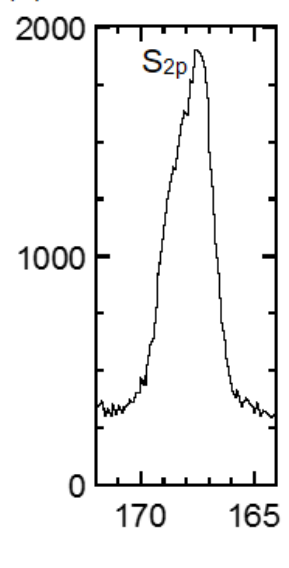

Figure S2. XPS spectra of (a) wide scan and high-resolution scan of (b) $\mathrm{O}_{1 \mathrm{~s}}$, (c) $\mathrm{F}_{1 \mathrm{~s}}$, (d) $\mathrm{K}_{2 \mathrm{p}}$ and $\mathrm{C}_{1 \mathrm{~s}}$, and (e) $\mathrm{S}_{2 \mathrm{p}}$ region of the line-patterned poly(SPMK) brush/FAS monolayer surface. The line widths of the brush and monolayer were $10 \mu \mathrm{m}$ and $5 \mu \mathrm{m}$, respectively. The brush thickness in the dry state was $39 \mathrm{~nm}$. Atomic rations of each element measured from peak areas of the high-resolution spectra were shown in (a). 


\section{S4. Molecular simulation}

Stability energies of solvation were calculated by molecular simulations using a molecular simulation software Materials Studio (Dassault System Co. Ltd.). Structural optimization calculations of each negatively charged sulfopropyl methacrylate (SPM) unit, positively charged EMI, and water molecule were performed based on the density functional theory (DFT). The most stable position and structure of systems containing "SPM and EMI" and "SPM and water" were calculated using classical molecular dynamics (MD), as shown in Figure S3.

More specifically, the stable conformations of SPM unit, EMI, and water molecule were calculated by DFT ( $\mathrm{DMol}^{3}$ package, geometry optimization, quality: fine, energy tolerance $1.0 \times 10^{-5}$ Hartree, force and displacement tolerances are 0.002 Hartree $/ \AA$ and $0.005 \AA$, functional: GGA/PBE. Solvent was not specified.). The SPM unit and EMI were given charges -1 and +1 , respectively. The total energy of the SPM unit was calculated and the value was denoted as ESPM. One molecule of the EMI or water were initially placed $0.4 \mathrm{~nm}$ from the sulfonate anion of SPM, and the most stable position and structure were calculated by MD (Forcite, geometry optimization, quality: fine, forcefield: COMPASSII. Charges was used current ESP values calculated by DFT). Subsequently, the structural optimization calculations based on DFT were repeated. Distances of 0.38 and $0.34 \mathrm{~nm}$ between the sulfonate anion and the EMI cation and water were obtained, respectively, as shown in the multi-directional diagram of the simulation results (Figure S3). Each atomic charge calculated by DFT shown in Table S1-S3. The total energy of a system containing the SPM and the EMI is denoted as $E_{\text {SPM-EMI, }}$ and the energy difference $\Delta E_{\text {SPM-EMI }}=-1.50 \times 10^{-15} \mathrm{~J}$ between $E_{\text {SPM-EMI }}$ and $E_{\text {SPM }}$ was estimated. In addition, the energy difference $\Delta E_{\text {SPM-water }}=-0.33 \times$ $10^{-15} \mathrm{~J}$ of a system consisting of the SPM and the water molecule was calculated. 
SPM and EMI

$(\mathrm{a}-1)$

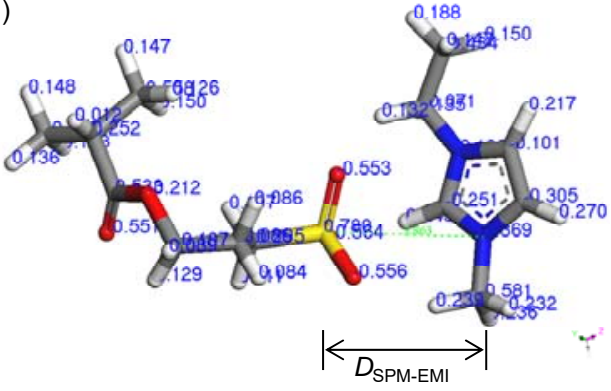

$(a-2)$

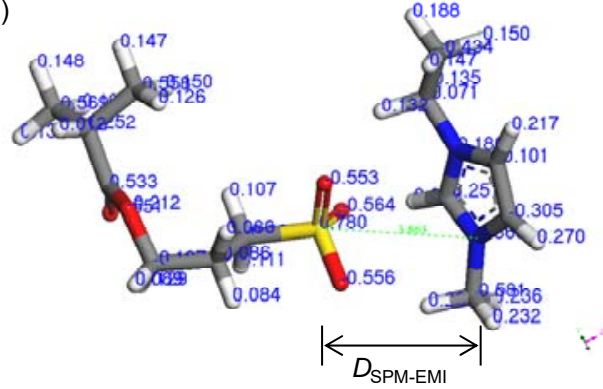

(a-3)

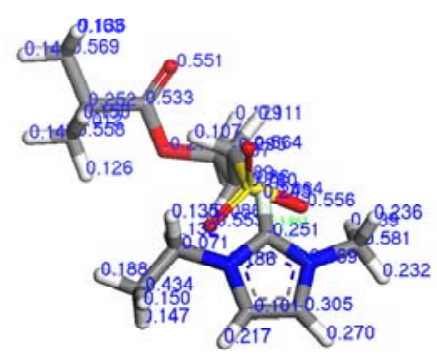

$(\mathrm{a}-4)$

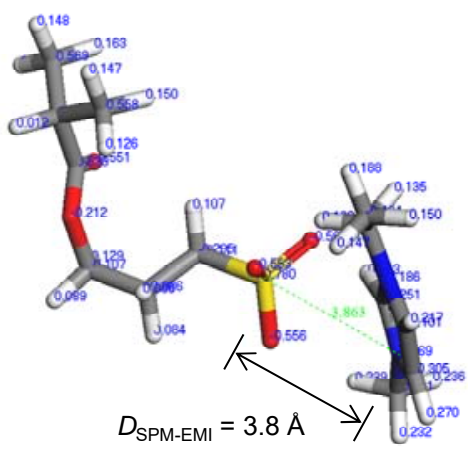

SPM and water

(b-1)

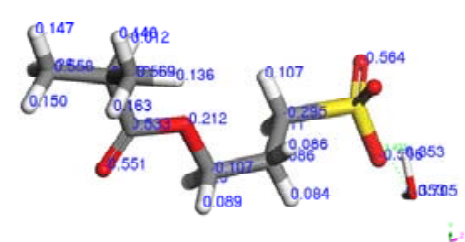

$(\mathrm{b}-2)$

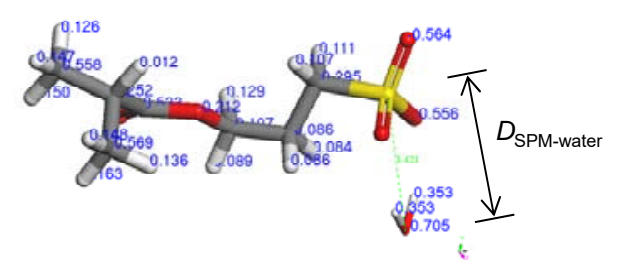

(b-3)

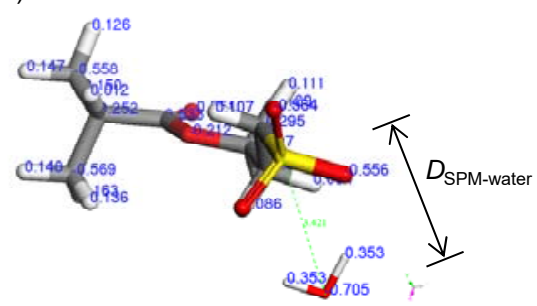

$(\mathrm{b}-4)$

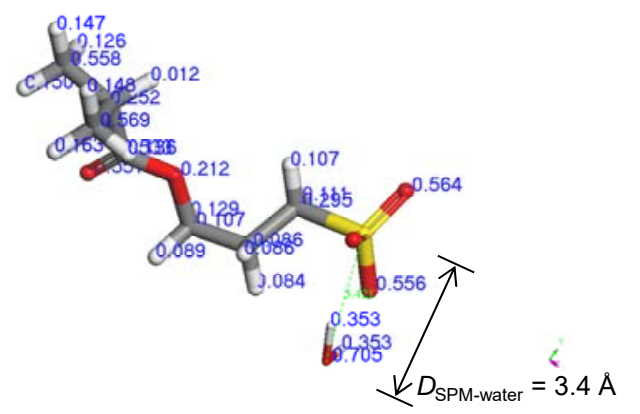

Figure S3. The most stable conformations of (a-1) - (a-4) SPM unit and EMI, and (b-1) (b-4) SPM unit and water. The objects in Figure (a-1) - (a-4) are same component with same conformation, but captured from different view angles. The objects in Figure (b-1) (b-4) also show the same conformation captured from different view angles. The DSPM-EMI and $D_{\text {SPM-water }}$ are distance between the sulfur atom in $\mathrm{SO}^{3-}$ and the nitrogen atom of EMI, and distance between the sulfur atom and the oxygen atom in water, respectively. The electric charge was shown on each atom. 
Table S1. Atomic charges of SPM ${ }^{a}$ unit calculated by DFT. ${ }^{b}$

\begin{tabular}{|c|c|c|}
\hline & Type & Charge \\
\hline $\mathrm{C} 1$ & $\mathrm{c} 4$ & -0.558 \\
\hline $\mathrm{C} 2$ & $\mathrm{c} 43$ & 0.252 \\
\hline $\mathrm{C} 3$ & c3' & 0.533 \\
\hline $\mathrm{O} 1$ & $\mathrm{o} 1=$ & -0.551 \\
\hline $\mathrm{C} 4$ & $\mathrm{c} 4$ & -0.569 \\
\hline $\mathrm{H} 1$ & h1 & 0.147 \\
\hline $\mathrm{H} 2$ & h1 & 0.150 \\
\hline H3 & h1 & 0.148 \\
\hline $\mathrm{H} 4$ & h1 & 0.136 \\
\hline H5 & h1 & 0.163 \\
\hline $\mathrm{O} 2$ & $02 \mathrm{~s}$ & -0.212 \\
\hline $\mathrm{C} 5$ & $\mathrm{c} 4 \mathrm{o}$ & -0.107 \\
\hline C6 & $\mathrm{c} 4$ & -0.086 \\
\hline $\mathrm{C} 7$ & $\mathrm{c} 4$ & -0.295 \\
\hline $\mathrm{S} 1$ & $\mathrm{~s} 4 \mathrm{i}$ & 0.780 \\
\hline $\mathrm{O} 3$ & $\mathrm{o} 1$ is & -0.564 \\
\hline $\mathrm{O} 4$ & $\mathrm{o} 1$ is & -0.553 \\
\hline O5 & $\mathrm{o} 1$ is & -0.556 \\
\hline H6 & h1 & 0.129 \\
\hline $\mathrm{H} 7$ & h1 & 0.089 \\
\hline H8 & h1 & 0.086 \\
\hline H9 & h1 & 0.084 \\
\hline H10 & h1 & 0.107 \\
\hline H11 & h1 & 0.111 \\
\hline $\mathrm{H} 12$ & h1 & 0.012 \\
\hline H13 & h1 & 0.126 \\
\hline
\end{tabular}

${ }^{a}$ Sulfopropyl methacrylate anion. The total charge was $-0.998 .{ }^{b}$ Density functional theory. 
Table S2. Atomic charges of EMI ${ }^{a}$ calculated by DFT. ${ }^{b}$

\begin{tabular}{|c|c|c|}
\hline & Type & Charge \\
\hline H1 & h1 & 0.270 \\
\hline N1 & $\mathrm{n} 3 \mathrm{a}+\mathrm{d}$ & 0.369 \\
\hline $\mathrm{C} 1$ & $\mathrm{c} 3 \mathrm{a}$ & -0.251 \\
\hline $\mathrm{N} 2$ & $\mathrm{n} 3 \mathrm{a}+\mathrm{d}$ & 0.186 \\
\hline $\mathrm{C} 2$ & $\mathrm{c} 3 \mathrm{a}$ & -0.101 \\
\hline $\mathrm{C} 3$ & $\mathrm{c} 3 \mathrm{a}$ & -0.305 \\
\hline $\mathrm{H} 2$ & h1 & 0.243 \\
\hline $\mathrm{H} 3$ & h1 & 0.217 \\
\hline $\mathrm{C} 4$ & $\mathrm{c} 4$ & -0.434 \\
\hline $\mathrm{C} 5$ & $\mathrm{c} 4$ & -0.071 \\
\hline $\mathrm{H} 4$ & h1 & 0.150 \\
\hline H5 & h1 & 0.147 \\
\hline H6 & h1 & 0.188 \\
\hline $\mathrm{H} 7$ & h1 & 0.135 \\
\hline $\mathrm{H} 8$ & h1 & 0.132 \\
\hline C6 & $\mathrm{c} 4$ & -0.581 \\
\hline H9 & h1 & 0.232 \\
\hline H10 & h1 & 0.236 \\
\hline H11 & h1 & 0.239 \\
\hline
\end{tabular}

${ }^{a}$ 1-Ethyl-3-methylimidazolium cation. The total charge was $1.001 .{ }^{b}$ Density functional theory.

Table S3. Atomic charges of water ${ }^{a}$ calculated by DFT. ${ }^{b}$

\begin{tabular}{ccc}
\hline & Type & Charge \\
\hline O1 & o2* & -0.705 \\
H1 & h1o & 0.353 \\
h1o & 0.353 \\
\hline
\end{tabular}

${ }^{a}$ The total charge was $0.001 .{ }^{b}$ Density functional theory. 